emulsions stored at $10^{\circ} \mathrm{C}$., for the shortest time, alike again by both portions, by emulsions stored at $37^{\circ} \mathrm{C}$.; and (b) that the potency as between the chloroformed and glycerinated vaccine kept at any one of the foregoing temperatures was practically the same, the only marked difference occurring in case of the vaccines kept at $37^{\circ} \mathrm{C}$, a temperature at which the chloroformed emulsions retained potency for a longer period than did the glycerinated emulsions.

Upon the completion of the foregoing experiments, a further number of vaccines collected from vesicles of good average quality were emulsified with water in the proportion of one part by weight of pulp to two parts by weight of water, and subjected as before to the chloroform process. When elimination of their extraneous bacteria had been effected part of the chloroform was removed from the emulsions and these were placed in the ice-chest at $10^{\circ} \mathrm{C}$. Immediately prior to the issue of these vaccines the remainder of the chloroform was removed and glycerine was added in the proportion of two parts by weight of glycerine to the original weight of vaccine pulp. These vaccines were later, after passing the requisite tests, issued for general vaccinating purposes, a similar interval being allowed to elapse between their collection from the calf and subsequent issue as is usual at these laboratories in the case of glycerinated vaccine-namely, about six weeks. In the case of two of these chloroformed vaccines an interval of two months elapsed between collection and issue. The use of these chloroformed vaccines has been attended with results showing high "case" and "insertion" success.

Summary. - Experience of the further use of the chloroform process in the preparation of a large number of vaccines during the past year confirms the conclusions arrived at in the preliminary note. And meanwhile important additional knowledge has been gained-namely, that chloroformed calf vaccine, if originally of sufficiently high potency, will, when prepared and stored under suitable conditions, retain for a considerable time a high degree of potency and this notwithstanding that the extraneous organisms had been rapidly eliminated from it in an early stage of its preparation.

\section{WOUND OF THE LEFT THORAX, WITH EXTENSIVE LACERATION OF THE PLEURA, ETC.}

BY E. WYNSTONE-WATERS.

ON March 20th, at about 2.30 A.M., I was awakened by the arrival of a number of natives at $m y$ house and $I$ soon discovered that one of them, a man of about 25 years of age, had received a severe wound with a native knife. The wound occupied the left ninth intercostal space, its direction being oblique and parallel to the ninth rib, and extended posteriorly somewhat beyond the posterior axillary line, while in front it reached the anterior axillary line. The wound implicated the parietal pleura in nearly its whole length, except posteriorly where the incision became more superficial. The visceral pleura was also implicated, but to a less extent, and the lung tissue was lacerated. At the time I made the examination there were very considerable hæmorrhage and at first a marked whistling sound which, however, soon became indistinct. Pneumothorax was established, air having rushed in and separated the parietal and visceral pleura, and the lung was somewhat collapsed in virtue of its elasticity.

The wound having been thoroughly cleansed I did not attempt to reduce its size, thus being certain of a more efficient drainage and at the same time obtaining a larger field for observation. On the next day on removing the dressings I found that a considerable amount of hrmorrhage had occurred, while the external aperture was filled by a closely fitting plug of lung tissue which protruded somewhat beyond the external surface. No attempt was made to reduce this protrusion but it was kept thoroughly aseptic. The protruded lung was quite healthy and showed considerable crepitation due to the residual air. On the fourth day slight but steady pressure was applied to the protruded lung tissue and a firm compress of carbolic tow was strapped over the part. On the fifth day on removing the dressings I found that the lung tissue had yielded to the continued pressure of the compress and was inside the thoracic cavity. Shortly after this granulations were seen to be rapidly springing up all round. The area at first occupied by the plug of lung now presented a pink field of healthy newly formed tissue, only a very slight amount of pus being present on the dressings. The wound was kept plugged with cyanide gauze, so that the cavity was filled with healthy tissue from the very bottom, there being no opportunity for the development of any sinuses or other false cavities. Skin gradually spread from the edges of the wound and was soon seen to cover up the whole site of the lesion, except where a few exuberant granulations prevented its further encroachment. These islands of new tissue, however, soon yielded to a few touches from a crystal of blue stone and the skin rapidly covered up. their original site.

This case is one of exceeding interest to the physiologist as well as to the pathologist and surgeon, showing nature in one of her happiest moods. The patient belongs to the Waswahili, a subdivision of the Bantu section of the African negro, a race occupying a "thin line along a thousand miles of creeks and islands" on the East coast of Africa. The protruding portion of lung by its constant pressure caused inflammatory adhesion to take place between the visceral and parietal pleura along the line of pressure, thus completely sealing ap the rent into the pleural cavity and establishing a continuity of parietal and visceral pleura-in fact, producing a condition resembling the normal pleura-viz., a closed sac. The air in this now closed sac becoming rapidly absorbed, the lung expanded and the parietal and visceral layers of the pleura coming into apposition the normal process of respiration was again established. Doubtless in time the inflammatory adhesion of the pleura at the peripheral margin will become fibrous and the exposed surface of lung, which has been forced to retire within its own cavity, will adhere and become united by fibrous tissue to the scar tissue filling the original wound. Thus, by a perfectly natural process, aided by strictly antiseptic precautions, an exceedingly severe and dangerous wound was closed, the only drawback or compensation nature will impose being a somewhat diminished "vital capacity" on the affected side.

Lamu, British Fast Africa, May, 1904.

\section{GYNACOMASTIA.}

By EDWIN S. CRISPIN, M.R.C.S. ENG., L.R.C.P. LOND., CIVIL SURGEON AND HON. BIMBASHI, EGYPTIAN ARMY.

I READ with interest the article on Gynæcomastia in THE LANCET of March 26th, p. 865, by my colleagues, $\mathrm{Mr}$. A. Webb Jones and Dr. J. B. Christopherson as I happened to be at Merowi when I received that number of THE LANCET where Case 1 is still at work and where also $I$ found a third case. I regret that I was unable to get a photograph of the latter as $I$ had not my camera with me; he has a distinct gland in each breast of the size of a small Tangerine orange which can be easily moved over the muscles of the chest the nipples are also well developed. He also is a Sudanese, a Nubawi, Case 1 being a Furawi, not a Firtitawi, as mentioned in that article, but, howerer, they all come from the neigbbourhood of Darfur.

I believe that gynæcomastia is not at all an uncommon condition amongst the Sudanese of Central Africa. I saw two or three more cases amongst the Dinkas and Baris while I was travelling on the Bahr-el-Ghebel between Lake No and Gondokoro. Sir Harry Johnston in his book, "British Central Africa," gives a very good reproduction of a photograph of a similar case on p. 399 and says it is very common amongst Sudanese. I do not think that he can have confused these cases with those of prominent pectoral development of fat and muscle, as a digital examination would at once settle the diagnosis, but in a photograph these cases are very similar. I inclose a photograph taken by Dr. J. Warnock of the Egyptian Asylum, of a case of this latter sort, the 